\title{
Chapter 10 \\ The Choice Is Between Mental Health and Mental Illness
}

\begin{abstract}
...The United States hasn't lost ground; the ship of state is pointed in the wrong direction, and the rest of the world has moved on. Global concerns about U.S. credibility aren't simply tied to the calamitous presidency of Donald Trump-they're rooted in the fact that the American people elected someone like Trump in the first place. Having seen Americans do that once, foreign leaders and publics will wonder whether the United States might do it again, particularly given the fealty of the Republican party to Trump's authoritarian brand of politics...
\end{abstract}

Even though the 2020 election has been decided, the issues underlying it will be around for a long time. For this reason, we return once again to the topic of Leadership and examine it from the standpoint of a different perspective on Mental Health.

The choice in the 2020 Presidential election couldn't have been any clearer. It's fundamentally a choice between Mental Health and Mental Illness. And, it will be forever more.

As scholars and practitioners, for over 50 years, we have observed firsthand what true Leadership is about. Unlike simple, well-defined problems, as exemplified by textbook or classroom exercises that have one and only one right answer, and in theory can be solved by just one person acting alone, genuine Leadership requires the ability to bring together diverse groups of recognized experts in order to address complex, messy, and ill-defined problems, in short, Wicked Messes. It requires a healthy culture, whereby the experts are not only free, but actively encouraged, to openly express their true differences and opinions and thus to respectfully challenge one another. Most of all, it requires a leader who is comfortable with the basic fact that a diverse group of experts knows more than he or she could possibly know on their own.

\footnotetext{
${ }^{1}$ Ben Rhodes, "The Democratic Renewal: What It Will Take to Fix U.S. Foreign Policy," FOREIGN AFFAIRS, September/October, 2020, p 46.
} 
By definition, complex problems exceed the knowledge and capabilities of anyone no matter how well-qualified or intelligent they are. This pertains especially to the office of the Presidency where the most inordinately complex problems arrive by the minute. As we've stressed throughout, they are made complex by the fact that the Economic, Ecological, International, Political, and Public Health problems we face are not only deeply intertwined, but are fundamentally inseparable. They are parts of a complex, messy system that must be dealt with as a whole. They cannot even be properly defined, let alone coped independently of one another.

But even more, in order to correctly define and effectively address complex, Wicked problems, character "trumps" policy (pun intended!). However wellintended, all of the policies in the world cannot make up for the absence of character and Mental Health. Leadership requires that one fundamentally be in touch with Reality, is confident enough to actively encourage diversity and disagreement, and knows how to integrate the knowledge of diverse experts to result in effective solutions.

The fact that we've had a President who exhibits daily acute symptoms of multiple forms of Mental Illness, and in turn is further aided by Republican enablers, is cause for the gravest concern. Indeed, his condition has deteriorated constantly before our eyes.

The damage he's done is so egregious such that we couldn't endure four more years of it. It would be a national and international disaster from which we could never recover.

Simply put, Mental Illness irreparably distorts and manipulates Reality in the worst possible way. In the case of Donald Trump, his deep narcissistic "needs"more accurately "wounds"- govern his behavior, not the legitimate needs of the citizens. And, as a way of fending off direct assaults to The Self, his self-loathing is largely responsible for personal attacks on others. Along with his glaring ignorance and sheer incompetence about what it takes to address complex problems, all of the above dangerously combine to result in a sure-fire formula for failed policies and escalating national and international crises on a horrific scale.

He also lacks one of the most essential qualities of a leader, namely, Emotional Intelligence: the basic ability to experience and express empathy for others, to exhibit calm in the face of cataclysmic events, to unite not divide us, and to show proper respect toward friends and foes alike-not to utter a never-ending string of tasteless slurs and childish name-calling of respected experts who, based on their areas of expertise and experience, naturally have different points of view.

While one can acquire through proper education the fundamental knowledge and skills that the job of the President requires, the necessary emotional and social skills are not as easily obtained. They have to be instilled in childhood. If not, it takes a prolonged and dedicated course of Psychotherapy and other forms of Social/ Emotional Development to create a well-functioning human being who can work with others. But then, it also requires that one has enough emotional understanding of what's needed to take the necessary steps to heal one's own limitations and childhood wounds in order to become an empathic human being who can attend to the needs of others. We've seen no evidence whatsoever that Donald Trump has had any 
inclination to examine his life, become a better person, and thereby become a better leader. Indeed, he's made perfectly clear again and again that he's not capable of it.

Make no mistake about it: As much as any time in our history, the 2020 election has been a vote for Mental Health, human decency, genuine caring, real empathy, and the emotional ability to bring together, and actively listen to, diverse experts with both an open mind and an open heart. We've desperately needed a sane leader who can focus on the needs of the country and entire world, not himself. In short, we need someone who is Secure in every sense.

In short, we've needed a true leader who is strong enough to face hard truths about themselves so that we can face those same truths about ourselves-and act accordingly.

At the time of this writing, Trump and his supporters are not able to face the fact that he lost the 2020 election.

Open Access This chapter is licensed under the terms of the Creative Commons Attribution 4.0 International License (http://creativecommons.org/licenses/by/4.0/), which permits use, sharing, adaptation, distribution and reproduction in any medium or format, as long as you give appropriate credit to the original author(s) and the source, provide a link to the Creative Commons license and indicate if changes were made.

The images or other third party material in this chapter are included in the chapter's Creative Commons license, unless indicated otherwise in a credit line to the material. If material is not included in the chapter's Creative Commons license and your intended use is not permitted by statutory regulation or exceeds the permitted use, you will need to obtain permission directly from the copyright holder.

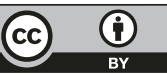

